See discussions, stats, and author profiles for this publication at: https://www.researchgate.net/publication/276130250

Do close range measurements affect the target strength (TS) of fish in horizontal beaming hydroacoustics?

Article in Fisheries Research · April 2015

DOI: $10.1016 / \mathrm{j}$.fishres.2015.03.020

CITATIONS

5

4 authors, including:

Vicky Rodríguez-Sánchez

Universidad de Sevilla

10 PUBLICATIONS 52 CITATIONS

SEE PROFILE
181

R. Sánchez-Carmona

Universidad de Sevilla

8 PUBLICATIONS 51 CITATIONS

SEE PROFILE 


\title{
Do close range measurements affect the target strength (TS) of fish in horizontal beaming hydroacoustics?
}

\author{
Victoria Rodríguez-Sánchez*, Lourdes Encina-Encina, Amadora Rodríguez-Ruiz, \\ Ramona Sánchez-Carmona
}

Department of Plant Biology and Ecology, Faculty of Biology, University of Seville, P.O. Box 1095, E-41080 Seville, Spain

\section{A R T I C L E I N F O}

\section{Article history:}

Received 30 September 2014

Received in revised form 24 March 2015

Accepted 26 March 2015

Available online xxx

\section{Keywords:}

Horizontal beaming hydroacoustics

Near-field

Target strength

Fish

\begin{abstract}
A B S T R A C T
Detailed fish target strength (TS) studies allow us to relate their physical and biological variables to their sound behaviour and they potentially improve the accuracy of acoustic assessments. One of the limitations of the transducers that are currently used is their difficulty to precisely estimate TS at close range, either because the acoustic beam may not include the whole fish or because of the near-field effect. When measuring the sound produced by a target (fish), it is recommended that the so-called near-field area, which is generated immediately in front of the target, should be avoided. In horizontal hydroacoustics, where information is obtained within the first $15-20 \mathrm{~m}$ from the transducer, avoiding this near-field area may render the majority of the sampled volume useless. This experiment was developed in order to study the horizontal behaviour of the TS with regard to distance. We have studied three different sizes of free-swimming large carps and barbels $(\approx 300,400$ and $500 \mathrm{~mm})$ and we have recorded fish traces at three distances from the transducer, both fulfilling and not fulfilling the requirements of the near-field (6, 9 and $12 \mathrm{~m}$ ). The results showed no differences in the mean TS obtained for fish at different distances. Factors such as orientation or size showed a greater influence on TS changes. These results are very encouraging and they support the use of hydroacoustics in studies performed at close range, such as studies of fish migration in rivers or biomass estimations in aquaculture.
\end{abstract}

(C) 2015 Elsevier B.V. All rights reserved.

\section{Introduction}

Hydroacoustics is a technique used as a tool for fish research both in freshwater (Yule, 2000; Wanzenbock et al., 2003; Godlewska et al., 2012, Dennerline et al., 2012) and marine systems (Fabi and Sala, 2002; Neilson et al., 2003; Axenrot et al., 2004; Greenstreet et al., 2010). In order to accurately assess fish density and biomass, it is essential to establish the relationship between the intensity of the sound backscattering from fish, which is known as target strength (TS dB re $1 \mathrm{~m}^{2}$ ), and the fish variables such as length or weight (Simmonds and MacLennan, 2005).

The use of hydroacoustics as a tool to study water systems is increasing since it has numerous advantages compared with other traditional methods. One of the most relevant advantages is that it is a non-invasive application that covers large areas with high spatial resolution and low manpower requirements (Simmonds and MacLennan, 2005; Godlewska and Jelonek, 2006). In spite of the advantages of hydroacoustic methods, there are some

\footnotetext{
* Corresponding author. Tel.: +34 954557065; fax: +34 954626308.

E-mail address: vrodriguez@us.es (V. Rodríguez-Sánchez).
}

disadvantages that may complicate the acquisition of accurate estimates of fish TS, especially in horizontal applications (with the transducer positioned parallel to the water surface).

Horizontal applications involve greater complexity and uncertainty than vertical applications since changes in the fish swimming orientations lead to significant TS changes. It is known that large variations have been encountered when fish swim from a lateral position to a head or tail position (Kubecka, 1994; Lilja et al., 2000, 2004; Frouzova et al., 2005; Boswell and Wilson, 2008; Pedersen et al., 2009; Rodríguez-Sánchez et al., 2015). Therefore, when horizontal applications are used, the study of these variations and their inclusion in TS-length relationships are fundamental.

Horizontal hydroacoustics is usually used to complement or complete vertical density and biomass estimates when, for example, fish are aggregated close to the surface or in shallow areas (Kubecka and Wittingerova, 1998; Yule, 2000; Knudsen and Saegrov, 2002). In these shallow systems, TS measurements may present deviations due to boundary effects (Mulligan, 2000) and a low signal-to-noise ratio (SNR) (Kieser et al., 2000). Boundary effects are produced by the direct reverberation of the sound wave that comes from the bottom and/or the surface of the water, 
which generates a noisy background. This affects the signal-tonoise ratio(SNR), which is the magnitude of the difference between the echoes coming from fish and the "unwanted" echoes coming from other non-fish sources within the water column (Simmonds and MacLennan, 2005). Therefore, when analyzing these systems, it is also important to take both effects into consideration.

On the other hand, one of the limitations of the transducers that are currently used is that the precise estimation of TS at close range is difficult, either because the acoustic beam may not include the whole fish or because of the near-field effect. The near-field is an unstable sound area that is generated close to the sound source in any object that emits a sound wave (Medwin and Clay, 1998). Therefore, this area is usually avoided in order to prevent bias in biomass estimations (Dawson et al., 2000; Mulligan, 2000; Simmonds and MacLennan, 2005).

Besides the near-field of the acoustic transducers, the ensonified fish also have a near-field that is directly related to their length (i.e., large fish have large near-fields) (Medwin and Clay, 1998). The combined near-fields of the transducer and the fish can be a substantial proportion of the distance between the transducer and the fish and they could render hydroacoustics useless because of the reduction of the effective ensonified volume, especially in systems where large fish are an important component of the fish community. In summary, horizontal sampling is limited by the noise and the volume available for analysis is considerably reduced when the usable volume is limited by the SNR and the near-field area is removed.

Studies dealing with this issue are scarce and there is little information about how the aforementioned theoretical limitations affect real data and whether the bias of the combined near-fields of the transducer and the fish leads to serious errors in the collected data. In this study, two species were used to test this effect: Luciobarbus sclateri and Cyprinus carpio. These species were selected because of their importance in fish assemblages in European freshwater systems (Encina et al., 2006). Due to their large size and abundance, both species significantly contribute to the total biomass of these systems and, therefore, their acoustic study may be useful for biomass estimations.

The aim of this study was (i) to evaluate TS changes of large barbels and carps in relation to their swimming angles, species and distances from the transducer and (ii) to determine which of the studied distances produce reliable measurements of TS for large fish.

\section{Material and methods}

\subsection{Fish collection and experimental setup}

The study was conducted with two fish species: Andalusian barbel (Luciobarbus sclateri) and common carp (Cyprinus carpio). Specimens of these two species were collected from anglers in the inner harbour of the Guadalquivir River. After collection, fish were anaesthetised with clove oil to prevent injury during transportation to the experiment site (García-Gómez et al., 2002). Before the recordings, the standard length $(\mathrm{SL})$ and weight $(\mathrm{W})$ of the fish were measured in millimetres and grams, respectively.

Three individuals from each species were selected for the experiment. The standard lengths of the ensonified fish were $\approx 300,400$ and $500 \mathrm{~mm}$ (Table 1 ). The fish were placed individually in the experimental cage so that overlapping echoes from multiple targets were not falsely accepted as valid echoes from the same track. They remained in the cage for $24-96 \mathrm{~h}$ in order to obtain enough data for the statistical analysis.

The experimental cage was a cube with a side length of $1.5 \mathrm{~m}$. It was made from PVC pipe with holes in order to let the water
Table 1

Near-field distances calculated for three different sizes of barbel and carps and state of the theoretical requirements for accurate TS measurements.

\begin{tabular}{|c|c|c|c|c|c|c|c|c|c|c|}
\hline & \multirow[t]{3}{*}{$\mathrm{SL}(\mathrm{mm})$} & \multirow[t]{3}{*}{$\mathrm{SbL}(\mathrm{mm})$} & \multirow[t]{3}{*}{$\mathrm{D}_{\mathrm{SL}}(\mathrm{m})^{\mathrm{a}}$} & \multirow[t]{3}{*}{$\mathrm{D}_{\mathrm{SbL}}(\mathrm{m})^{\mathrm{a}}$} & \multicolumn{6}{|c|}{ State of requirements } \\
\hline & & & & & \multicolumn{3}{|c|}{ Relative to SL } & \multicolumn{3}{|c|}{ Relative to Sb } \\
\hline & & & & & $6 \mathrm{~m}$ & $9 \mathrm{~m}$ & $12 \mathrm{~m}$ & $6 \mathrm{~m}$ & $9 \mathrm{~m}$ & $12 \mathrm{~m}$ \\
\hline \multirow[t]{3}{*}{ Barbel } & 350 & 106.0 & 4.37 & 0.38 & $\mathrm{~F}$ & $\mathrm{~F}$ & $\mathrm{~F}$ & $\mathrm{~F}$ & $\mathrm{~F}$ & $\mathrm{~F}$ \\
\hline & 420 & 124.0 & 6.04 & 0.52 & $\mathrm{U}$ & $\mathrm{F}$ & $\mathrm{F}$ & $\mathrm{F}$ & $\mathrm{F}$ & $\mathrm{F}$ \\
\hline & 500 & 150.0 & 8.56 & 0.77 & $\mathrm{U}$ & $\mathrm{U}$ & $\mathrm{F}$ & $\mathrm{F}$ & $\mathrm{F}$ & $\mathrm{F}$ \\
\hline \multirow[t]{3}{*}{ Carp } & 325 & 112.3 & 3.61 & 0.43 & $\mathrm{~F}$ & $\mathrm{~F}$ & $\mathrm{~F}$ & $\mathrm{~F}$ & $\mathrm{~F}$ & $\mathrm{~F}$ \\
\hline & 400 & 142.0 & 5.47 & 0.69 & $\mathrm{U}$ & $\mathrm{F}$ & $\mathrm{F}$ & $\mathrm{F}$ & $\mathrm{F}$ & $\mathrm{F}$ \\
\hline & 525 & 181.0 & 9.43 & 1.12 & $\mathrm{U}$ & $\mathrm{U}$ & $\mathrm{F}$ & $\mathrm{F}$ & $\mathrm{F}$ & $\mathrm{F}$ \\
\hline
\end{tabular}

SL, standard length; SbL, swim bladder length; $D_{S L}$ near-field calculated from standard length; $D_{S b L}$ near-field calculated from swim bladder length; $F$, fulfilled requirements; $U$, unfulfilled requirements.

a The near-field of the transducer $(0.65 \mathrm{~m})$ needs to be added to the near-field calculated from both standard and swim bladder length in all distances.

pass inside, thereby avoiding undesirable air bubbles (Hartman and Nagy, 2005). The cage was covered by a mesh ( $5 \mathrm{~mm}$, knot to knot). A calibration test was performed in order to ensure that there were no significant echo returns coming from the cage. The test involved performing a horizontal calibration for all the studied distances and collecting recordings of the calibration sphere at three different positions with respect to the cage: in front of the cage, in the middle of the cage and behind the cage. Phase files of these recordings were analysed and the mean phase deviation ( $-6 \mathrm{~dB}$ level) was lower than 0.45 for both Athwart-ship and Along-ship positions in every case.

The frame was located in front of the transducer at the selected distances: 6,9 and $12 \mathrm{~m}$. The first distance was set at $6 \mathrm{~m}$ in order to allow the diameter of the acoustic beam cross section for a complete ensonification of the largest fish. The cage was placed in the old lock of the inner harbour of the Guadalquivir River. This location provided us with an area protected from the wind and tidal current, which is ideal for performing TS experiments (Gangl and Whaley, 2004).

TS data were recorded with a Simrad EK60 scientific echosounder (Simrad Kongsberg Maritime AS, Horten, Norway) equipped with a $200-\mathrm{kHz}$ circular split-beam transducer (ES2007C). The transducer was aimed horizontally, parallel to the water surface. It was fixed on a stainless steel bar anchored to the bottom by ballast at a depth of $1.5 \mathrm{~m}$. In addition, the anchored bar was tied to a tree with ropes in order to maintain its position (Fig. 1). The transducer depth was selected so that the main axis could cross the centre of the cage. The acoustic unit was calibrated with a 13.7mm copper sphere $(\mathrm{TS}=-45 \mathrm{~dB}$ ) following the standard calibration method (Foote et al., 1987). Transceiver settings are listed in Table 2. Data were stored on a PC and later processed with the Sonar5 Pro v.6.0.1 analysis software (Balk and Lindem, 2011).

\subsection{Acoustic processing and near-field calculation}

In order to eliminate noise and to ensure that we obtained as many detections as possible, the single echo detector parameters for the echosounder were set to accept echoes with the settings

Table 2

Settings of the echosounder during horizontal target strength (TS) measurements.

\begin{tabular}{lc}
\hline Type of transducer & ES-200-7C \\
Transmission frequency $(\mathrm{kHz})$ & 200 \\
Transmitting power $(\mathrm{W})$ & 150 \\
Pulse length (ms) & 0.128 \\
Ping rate (ping*s ${ }^{-1}$ ) & 10 \\
Minimum threshold (dB) & -70 \\
\hline
\end{tabular}




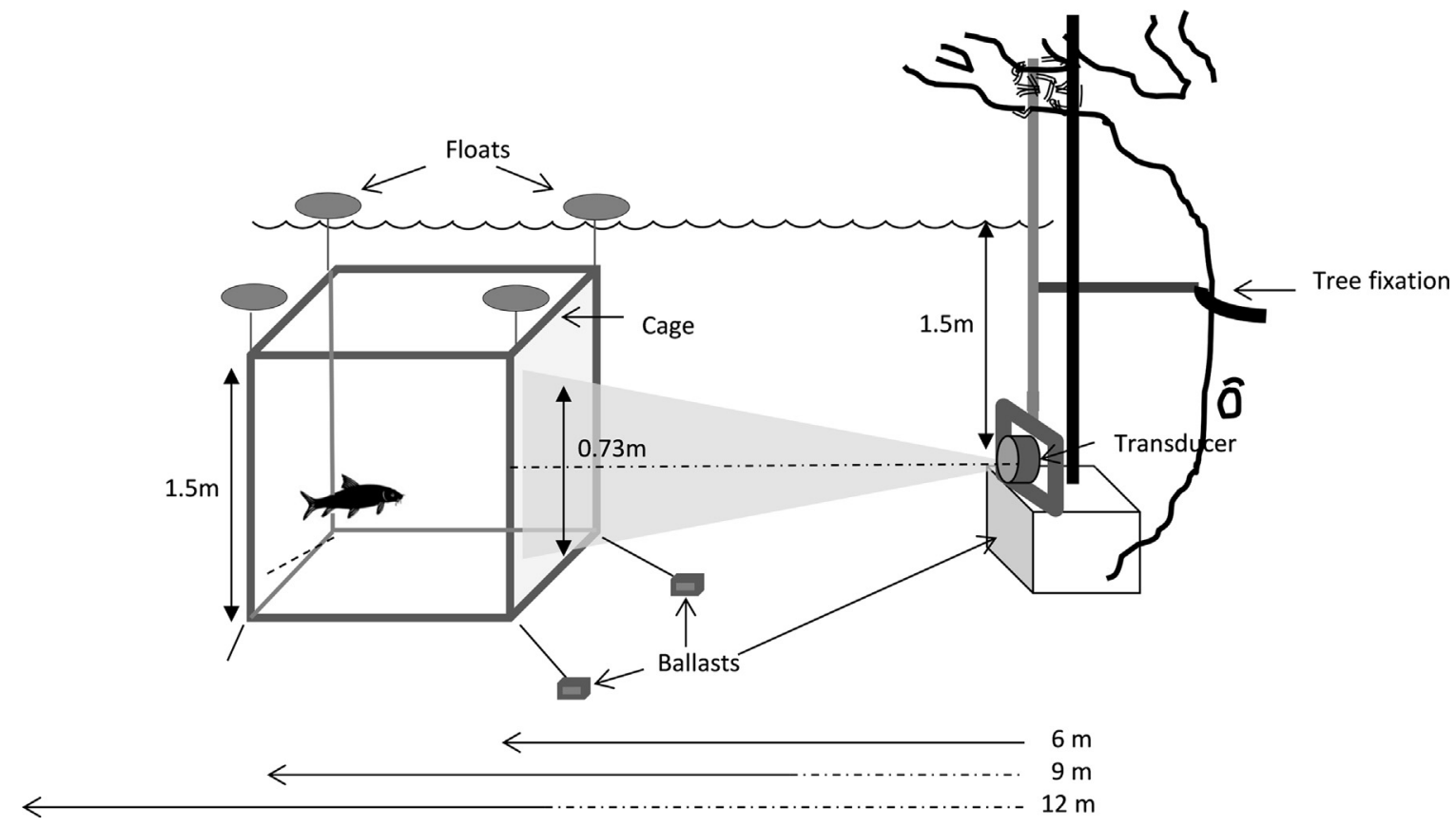

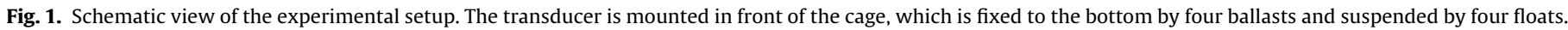

Table 3

Single echo detector settings used in the target strength analysis.

\begin{tabular}{ll}
\hline TVG & $40 \log R$ \\
Minimum TS (dB) & -55 \\
Min/max echo length (rel. to pulse length) & $0.8 / 1.6$ \\
Maximum gain compensation (one way) (dB) & -3
\end{tabular}

listed in Table 3. The analysis used TS measurements corrected depending on their angular location in the beam (i.e. off-axis compensated TS).

Tracks were selected using the manual tracking tool from the analysis menu (Balk and Lindem, 2011). In order to be accepted as valid tracks, the targets had to be separated from the previous ones by more than three pings and each track needed to contain at least five echoes (Henderson et al., 2007). Given that natural fish movements produce changes in TS, only linear fish tracks were analysed in order to filter those convex-concave oscillations and reduce bias in TS (Pedersen et al., 2009).

At the studied distances (6, 9 and $12 \mathrm{~m}$ ), the volume occupied by the beam was included in the volume occupied by the cage, i.e. the beam did not protrude out of the cage. Thus, we stored fish tracks from the entire beam width ( $-3 \mathrm{~dB}$ one way).

The mean TS of each track was calculated as the mean value of all echoes in a fish track. Mean TS was calculated in the linear domain as follows:

MfeanTS $=10 \cdot \log \left(\frac{1}{N} \sum_{i=1}^{N} 10^{T S i_{i} / 10}\right)$

The aspects of the fish tracks were calculated using the specific method developed by Rodríguez-Sánchez et al. (2015) and implemented in Sonar5-Pro. This method employs information from the whole track, removing the Y component of the track vector. The method uses $X Z$ positions from all echoes to calculate the regression line in the $\mathrm{XZ}$ plane. Then, it calculates the angle of the ensonified fish's swimming path with respect to the XY plane of the transducer. The aspect where the fish axis was perpendicular to the acoustic axis was fixed at $90^{\circ}$ (lateral aspect). The recorded tracks were divided into 18 categories of $10^{\circ}$ according to their aspect angle. Afterwards, the mean TS of each category was calculated. Subsequently, three angular regions were established and renamed according to their orientation: head/tail orientation (comprising angles between $0^{\circ}-20^{\circ}$ and $160^{\circ}-180^{\circ}$ ), oblique orientation (with angles between $20^{\circ}-70^{\circ}$ and $120^{\circ}-160^{\circ}$ ) and lateral orientation $\left(70^{\circ}-120^{\circ}\right)$.

The near-field of the applied transducer was 0.65 (Tichy et al., 2003). The fish near-field was calculated for each species' length (SL) by means of the following equation:

$D=r^{2} / \lambda$

where $r$ is the half-length of the fish (SL) and $\lambda$ is the length of the sound wave (Medwin and Clay, 1998). The calculated wave length $\lambda$ at $200 \mathrm{kHz}$ was $7.3^{*} 10^{-3} \mathrm{~m}$.

In order to recalculate the near-field distances from the area occupied by the swim bladder as well as to complement the acoustic measurements with information about the shape and volume of the swim bladder, fish were laterally and dorsally X-rayed after sound measurements. A portable Diagnostic X-ray Unit EcoRay Orange $1060 \mathrm{HP}$ was used to perform the radiographs at an intensity of $4 \mathrm{mAs}$ and $55 \mathrm{kv}$ during $1.2 \mathrm{~s}$. The lateral area of the swim bladder (A) and the lateral area of the body (B) were calculated for each fish (Fig. 2). We considered the lateral area of the fish to be only from the mouth to the root of the tail (standard length) because the fish tail scatters sound very weakly (Kubilius and Ona, 2012). The swim bladder area (A) and the body area (B) of the fish were calculated using the public domain Java image processing and analysis program IJ 1.46r (Rasband, 2014). The ratio between areas was calculated as follows: swim bladder area divided by body area and multiplied by 100 .

Table 1 shows the results of the near-field calculations and it specifies whether the theoretical requirements for accurate measurements of TS are fulfilled (F) or unfulfilled (U). When the conditions are fulfilled, the sum of the near-fields of the fish and the transducer is shorter than the distance between the fish and the transducer and, therefore, data should not be affected by the near-field effects. The opposite occurs when the conditions are unfulfilled. The first size $(\approx 300 \mathrm{~mm})$ was used as a reference since 

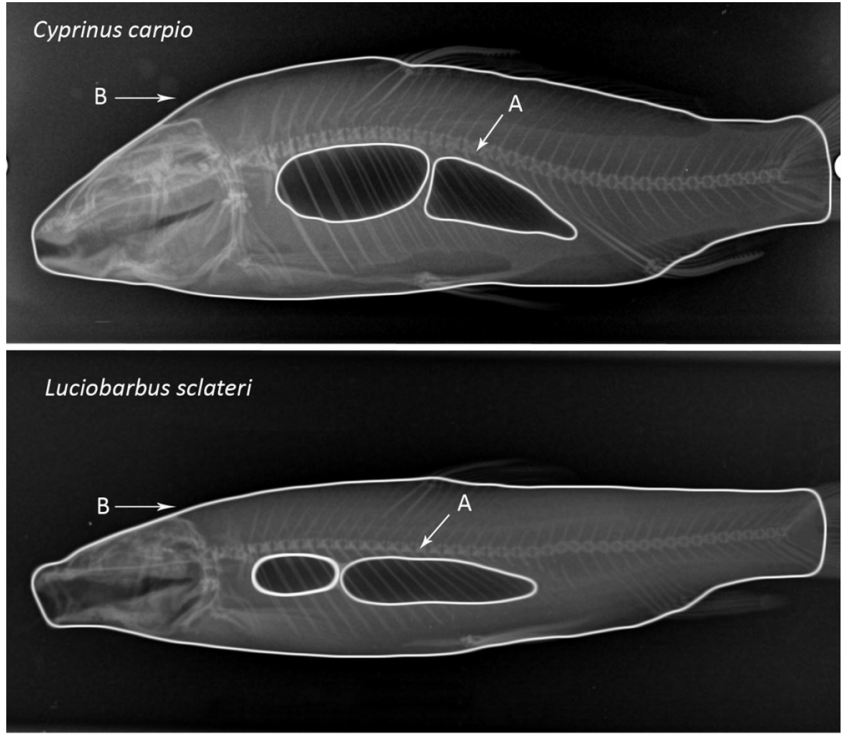

Fig. 2. Radiographs of Cyprinus carpio and Luciobarbus sclateri collected for this experiment in the inner harbour of the Guadalquivir River. The swim bladder area (A) and the body area (B) are highlighted.

it fulfilled the theoretical distance requirements for accurate TS measurements in every case.

\subsection{Statistical analysis}

The lateral TS values of each species were regressed against the logarithm of the standard length using the following relationship:

$\mathrm{TS}=a * \log _{10} L+b$

where TS is the target strength in $\mathrm{dB}, L$ is the standard length ( $\mathrm{mm}$ ) and $a$ and $b$ are regression constants.

A one-way analysis of covariance (ANCOVA) was conducted using all the selected tracks in order to test the effects of swimming orientation and species on the mean TS, with the total length as the covariate. Before the analysis, the homogeneity-of-regression (slope) assumption was tested.

A Kolmogorov-Smirnov goodness-of-fit test was used to test the normality of the lateral samples at each of the studied distances. As we expected that the near-field effect would not be constant for all distances and species, we conducted a two-way ANCOVA in order to study the influence of these two factors on the mean TS results, with the logarithm of the standard length as the covariate. Only mean TS obtained from fish lateral aspects were included in the analysis since lateral orientation exposes the largest area of swim bladder to sound. Every statistical analysis was performed by means of SPSS 20.0 (IBM SPSS, 2011).

\section{Results}

\subsection{Effects of body length, body aspects and species on mean TS}

In total, 764 tracks of barbels (397 with lateral orientation) and 844 of carps (493 with lateral orientation) were analysed. Significant linear regressions between lateral TS and standard length were obtained for both carps and barbels $\left(p<0.001 ; R^{2}\right.$ carp $=0.617$ and $R^{2}$ barbel $=0.452$ ). Therefore, the length was used as a covariate for subsequent analysis.

The homogeneity-of-regression assumption indicated that the relationship between the covariate and the dependent variable TS did not differ significantly as a function of swimming orientation $\left(F_{14.771}=0.033, p=0.968\right.$ for barbel and $F_{15.746}=1.019, p=0.431$ for

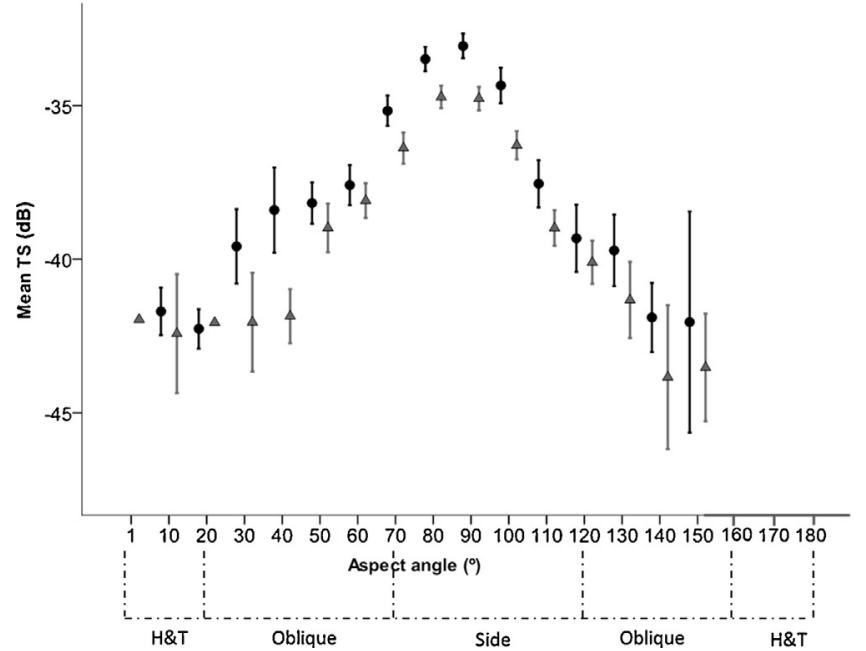

Fig. 3. Mean TS obtained for all the studied sizes classified by fish aspect angle and 95\% interval confidence. The solid circles represent mean TS for carp and the grey triangles represent mean TS for barbel.

carps $)$ or species $\left(F_{1.1515}=0.022, p=0.881\right)$. The mean TS was significantly influenced by the aspect angle (ANCOVA; $F_{14.676}=29.543$, $p<0.001$ for barbel and $F_{15.715}=22.224, p<0.001$ for carp, Fig. 3) and, consequently, changes in the fish swimming direction resulted in mean TS differences. The pattern of TS changes was similar for both carps and barbels, with an increase of TS as fish moved from a head/tail swimming position to a lateral position. The difference between the maximum and the minimum mean TS was almost $10 \mathrm{~dB}$ (Fig. 3). In both species, the highest TS values were obtained from lateral orientations and, among these lateral orientations; the highest values were obtained for angles ranging from $80^{\circ}$ to $100^{\circ}$. There were significant differences in mean TS values between species (ANCOVA: $F_{1.1516}=71.808, p<0.001$ ). Although the studied size range was similar between the species (Student's $t$ test; $p=0.895$ ), mean TS of carps was higher than that obtained for barbels in all aspects (Fig. 3). The average TS value for carps was -33.79 $(\mathrm{SD}=3.39)$ and the average TS for barbels was $-35.34 \mathrm{~dB}(\mathrm{SD}=3.25)$.

Both barbels and carps had two-chambered swim bladders. The ratio of the swim bladder and the lateral body areas ranged between 11 and $12.5 \%$ in carps and between 9 and 10\% in barbels. The ratios of carps were always higher than those of barbels, with an average difference of $2 \%$. This means that the proportion of the body occupied by the swim bladder was always larger in carps than in barbels.

\subsection{TS distributions at different distances from the transducer}

Lateral TS had a normal distribution and similar histograms in each of the studied species and distance combinations (Fig. 4). The results of the two-way ANCOVA used to test the influence of species and distance on the resulting TS are shown in Table 4. There is no significant interaction between the studied factors (species vs. distance) and, therefore, each of them can be independently interpreted. On the one hand, the mean TS for barbels was lower than that of carps at every studied distance $(p<0.001)$. On the other hand, there were no significant differences in the mean TS obtained at each of the studied distances ( $p=0.133$ ), regardless of species. In other words, TS values changed depending on the species, but they did not change with distance in any of the studied lengths. Thus, none of the sizes presented significant changes along distance.

For each specific lateral aspect angle and species, differences in TS among the studied distances were lower than $1 \mathrm{~dB}$, with the exception of carps with aspects ranging from $70^{\circ}$ to $80^{\circ}$ (Fig. 5). All 

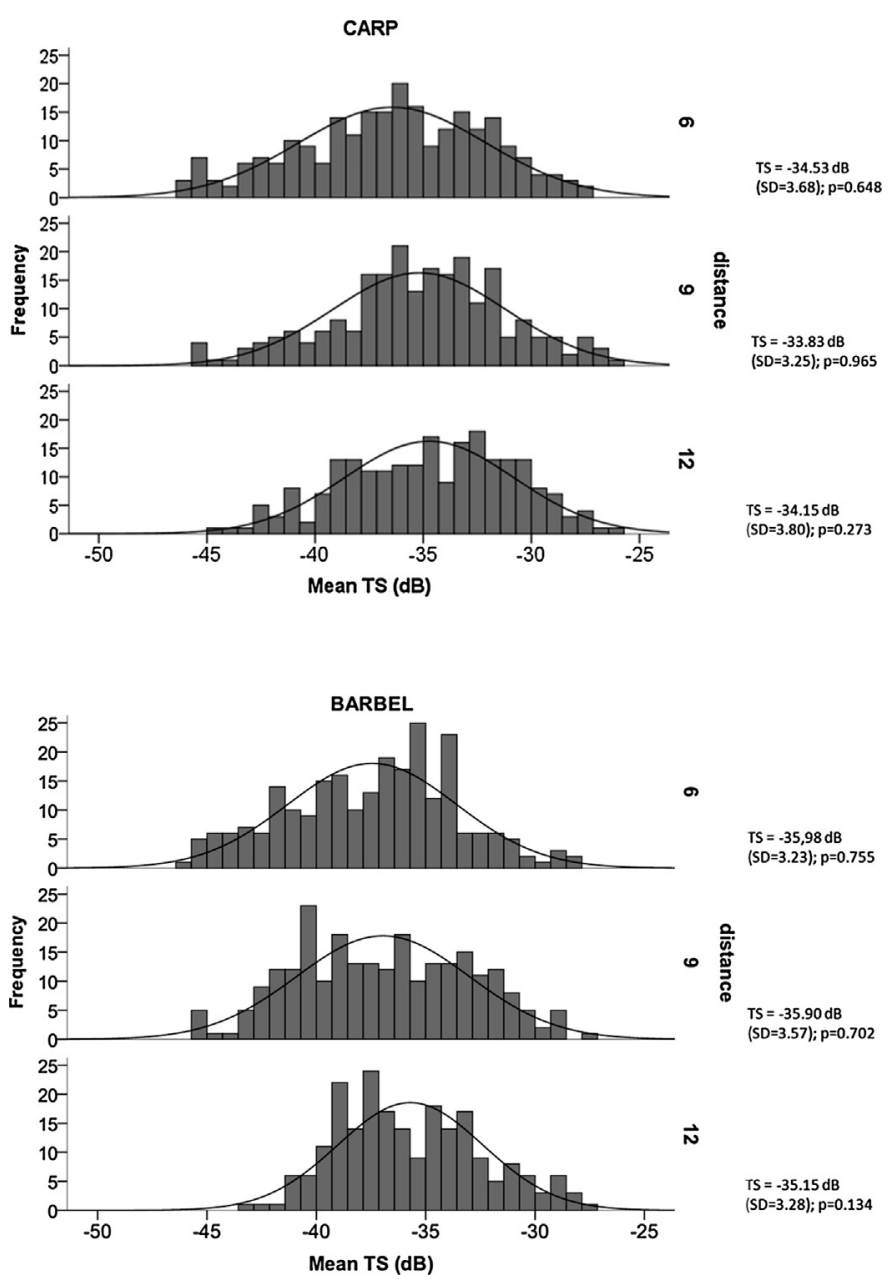

Fig. 4. Histograms of lateral TS recorded from all studied sizes of carp and barbel at different distances. Mean TS, standard deviation (SD) and significance $(p)$ for the Kolmogorov-Smirnov goodness-of-fit test.

Table 4

Effect produced by the fish species and the distance between the fish and the transducer on the resulting TS (with the logarithm of the standard length ( $\mathrm{mm}$ ) as the covariate).

\begin{tabular}{lcrrr}
\hline Parameter & Sum of squares & d.f. & \multicolumn{1}{c}{$F$} & \multicolumn{1}{l}{$P$} \\
\hline Log SL & 1122.7 & 1 & 102.05 & $<0.001$ \\
Species & 894.4 & 1 & 81.30 & $<0.001$ \\
Distance & 44.4 & 2 & 2.02 & 0.133 \\
Species*distance & 60.1 & 2 & 2.73 & 0.066 \\
Error & $11,100.8$ & 1009 & - & - \\
Corrected total & $12,924.3$ & 1015 & - & - \\
\hline
\end{tabular}

d.f., degree of freedom.

distances gave the maximun TS values when the fish were swimming with orientations between $80^{\circ}$ and $100^{\circ}$. The mean TS did not present any difference among the studied distances, regardless of the total length of the specimens.

\section{Discussion}

Previous studies have demonstrated the need to include horizontal beaming as a part of hydroacoustic fish stock surveys in natural freshwater systems (Kubecka and Wittingerova, 1998; Knudsen and Saegrov, 2002). In this regard, apart from establishing relationships between biological parameters and acoustic data, it is very important to understand sound behaviour when horizontal beaming is applied.
Our results prove that factors such as species, length and swimming orientation have a significant influence on the results of TS estimates. Therefore, they must be taken into account when analyzing acoustic data in horizontal samplings.

In agreement with previous studies, we confirm the importance of fish swimming orientation as a factor that affects the TS values in horizontal applications (Foote, 1980; Kubecka and Duncan, 1998; Burwen and Fleischman, 1998; Hazen and Horne, 2003; Frouzova et al., 2005; Henderson et al., 2007; Jech, 2011; Kubilius and Ona, 2012; Rodríguez-Sánchez et al., 2015). Lateral orientations gave consistently greater TS values than head and tail orientations. Therefore, information about orientation must be included in horizontal TS studies in order to obtain true fish biomass estimations. On the other hand, the accuracy of the results of acoustic samplings performed with horizontal orientations depends on the development of specific TS-length relationships.

The near-field area had already been identified as an issue that endangers the effectiveness and validity of horizontal hydroacoustics since fish are recorded at ranges where the theoretical requirements are unfulfilled (Dawson et al., 2000; Knudsen et al., 2004; Kubilius and Ona, 2012). Therefore, it was necessary to test the effectiveness of horizontal hydroacoustics at close range. It was not reasonable that a technique used in shallow areas and narrow channels or rivers had to avoid a near-field distance longer than $10 \mathrm{~m}$ with fish larger than $500 \mathrm{~mm}$ in order to record reliable data.

According to our results, the horizontal TS of large fish ensonified in lateral positions did not seem to depend on distance. After measuring the TS of different targets at different ranges, Dawson et al. (2000) and Knudsen et al. (2004) concluded that the standard near-field formulas overestimate the proportion of space occupied by the near-field effect. According to Knudsen et al. (2004) and the results obtained in this experiment, this voiding effect could be explained by swim bladder function, because it is responsible for most of the backscattered fish energy (Foote, 1980; Hazen and Horne, 2003). In our study, when the near-field is calculated based on the swim bladder, the theoretical requirements are fulfilled in every studied size and distance and the TS of specimens does not vary. This supports the theory that near-field calculation is overestimated and that it could be calculated based on the swim bladder. Moreover, if the near-field is calculated by taking swim bladder size into account rather than total body size, the volume available for the analysis of waterbodies increases, as does the applicability of horizontal hydroacoustics in acoustic samplings.

On the other hand, it could be expected that the TS of a big fish partially ensonified at close range be different from the TS obtained by the same fish from a greater distance, where the beam width would allow for its entire ensonification. However, our study shows that the TS of fish ensonified at close range is the same as that obtained from a greater distance. Therefore, at close ranges, if the swim bladder is included in the acoustic beam, the resulting TS could represent the whole fish, even when the size of the ensonified fish exceeds the diameter of the beam.

The fact that mean TS is lower in barbels than in carps is in accordance with the calculations of the swim bladder ratio since a barbel's swim bladder occupies a smaller relative volume than that of a carp. According to Frouzova et al. (2005) and Boswell and Wilson (2008), those differences in mean TS between species were most likely a result of the specific morphology of the species. However, those differences were not significant enough to render species discrimination feasible because, as the radiographs showed, morphological differences between species were not pronounced.

Our results highlight the usefulness and accuracy of density and biomass estimates obtained by means of horizontal hydroacoustics. They clarify previous speculations and represent a step forward in the understanding of sound behaviour for the detection of fish in shallow systems. 

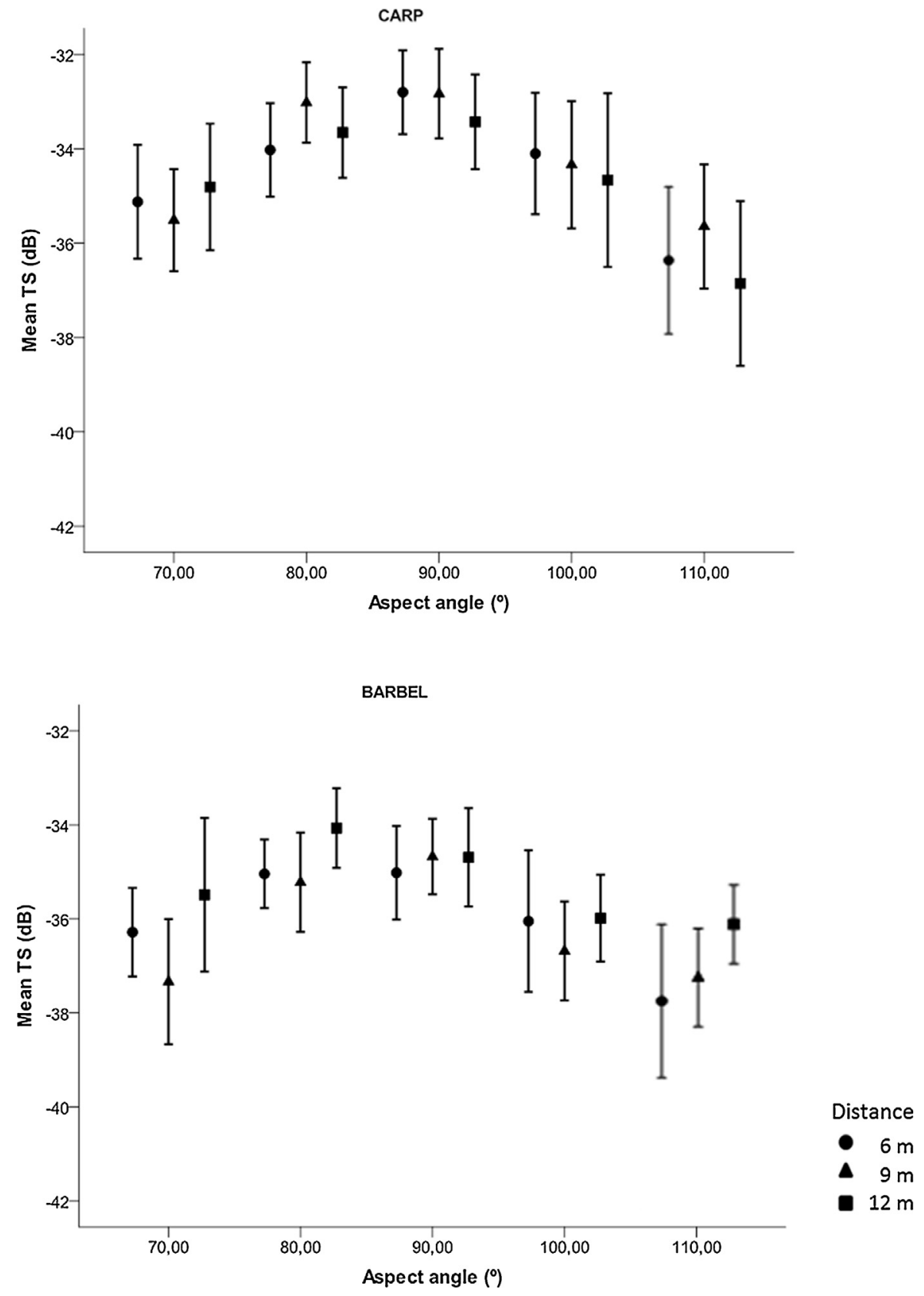

Fig. 5. Lateral mean TS recorded from the studied species at three different distances.

\section{Acknowledgements}

This study was carried out without funds thanks to the good will of the fish ecology group. We are grateful to Carlos Granado, Juan Ramon Cid and Carlos Orduna for their invaluable generosity and help with the field work. We are grateful to J.R. Rodríguez-Sánchez for his technical assistance in performing the radiographs. We thank the employees of the Inner Harbour of Seville and the Nautical Club of Seville for their logistical support. Our gratitude goes to Dr. Milan Riha and to the anonymous reviewers for improving this work with their valuable comments and inputs. We thank all those anonymous fishermen for supplying us with large fish. We also thank Cristina Ocaña for her careful proofreading of the English text. Special thanks go to all those who have contributed to this research in any way.

\section{References}

Axenrot, T., Didrikas, T., Danielsson, C., Hansson, S., 2004. Diel patterns in pelagic fish behaviour and distribution observed from a stationary, bottom-mounted, and upward-facing transducer. ICES J. Mar. Sci. 61, 1100-1104.

Balk, H., Lindem, T., 2011. Sonar 4 and Sonar 5-Pro post-processing systems. Operator manual version 6.0.2, 464 p. Lindem Data Acquisition Humleveien 4b. Oslo Norway.

Boswell, K.M., Wilson, C.A., 2008. Side aspect target strength measurements of bay anchovy (Anchoa mitchilli) and Gulf menhaden (Brevoortia patronus) derived from ex situ experiments. ICES J. Mar. Sci. 65, 112-120.

Burwen, D.L., Fleischman, S.J., 1998. Evaluation of side-aspect target strength and pulse duration as potential hydroacoustic discriminators of fish species in rivers. Can. J. Fish. Aquat. Sci. 55, 2492-2502.

Dawson, J.J., Wiggins, D., Degan, D., Geiger, H., Hart, D., Adams, B., 2000. Point-source violations: split-beam tracking of fish at close range. Aquat. Living Resour. 13, 291-295.

Dennerline, D.E., Jennings, C.A., Degan, D.J., 2012. Relationships between hydroacoustic derived density and gill net catch: implications for fish assessments. Fish. Res. 123-124, 78-89. 
Encina, L., Rodríguez, A., Granado-Lorencio, C., 2006. The Iberian ichthyofauna: ecological contributions. Limnetica 25 (1-2), 349-368.

Fabi, G., Sala, A., 2002. An assessment of biomass and diel activity of fish at an artificial reef (Adriatic sea) using a stationary hydroacoustic technique. ICES J. Mar. Sci. $59,411-420$

Foote, K.G., 1980. Averaging of fish target strength functions. J. Acoust. Soc. Am. 67 (2.), 504-515.

Foote, K.G., Knudsen, H.P., Vestnes, G.D., MacLennan, N., Simmonds, E.J., 1987. Calibration of acoustic instruments for fish density estimation: a practical guide. ICES Coop. Res. Rep. 144, 1-69.

Frouzova, J., Kubecka, J., Balk, H., Frouz, J., 2005. Target strength of some European fish species and its dependence on fish body parameters. Fish. Res. 75, 86-96.

Gangl, R.S., Whaley, R.A., 2004. Comparison of fish density estimates from repeated hydroacoustic surveys on two Wyoming waters. N. Am. J. Fish. Manage. 24, 1279-1287.

García-Gómez, A., de la Gándara, F., Raja, T., 2002. Utilización del aceite de clavo, Syzygium aromaticum L. (Merr. \& Perry), como anestésico eficaz y económico para labores rutinarias de manipulación de peces marinos cultivados. Boletín Inst. Esp. Oceanografía 18 (1-4), 21-23.

Godlewska, M., Jelonek, M., 2006. Acoustical estimates of fish and zooplankton distribution in the Piaseczno reservoir. Aquat. Ecol. 40, 211-219.

Godlewska, M., Frouzova, J., Kubecka, J., Wisniewolski, W., Szlakowski, J., 2012. Comparison of hydroacoustic estimates with fish census in shallow Malta Reservoir: which TS/L regression to use in horizontal beam applications. Fish. Res. 123-124, 90-97.

Greenstreet, S.P.R., Holland, G.J., Guirey, E.J., Armstrong, E., Fraser, H.M., Gibb, I.M., 2010. Combining hydroacoustic seabed survey and grab sampling techniques to assess local sandeel population abundance. ICES J. Mar. Sci. 67, 971-984.

Hartman, K.J., Nagy, B.W., 2005. A target strength and length relationship for striped bass and white perch. Trans. Am. Fish. Soc. 134, 375-380.

Hazen, E.L., Horne, J.K., 2003. A method for evaluating the effects of biological factors on fish target strength. ICES J. Mar. Sci. 60, 555-562.

Henderson, M.J., Horne, J.K., Towler, R.H., 2007. The influence of beam position and swimming direction on fish target strength. ICES J. Mar. Sci. 65, 226-237.

IBM Corp., 2011. Released, 2011. IBM SPSS Statistics for Windows, Version 20.0. Core systems user's guide. IBM Corp., Armonk, NY.

Jech, J.M., 2011. Interpretation of multi-frequency acoustic data: effects of fish orientation. J. Acoust. Soc. Am. 129 (1), 54-63.

Kieser, R., Mulligan, T., Ehrenberg, J., 2000. Observation and explanation of systematic split-beam angle measurement errors. Aquat. Living Resour. 13, 275-281.

Knudsen, F.R., Saegrov, H., 2002. Benefits from horizontal beaming during acoustic survey: application to three Norwegian lakes. Fish. Res. 56, 205-211.

Knudsen, F.R., Fosseidengen, J.E., Oppedal, F., Karlsen, O., Ona, E., 2004. Hydroacoustic monitoring of fish in sea cages: target strength (TS) measurements on Atlantic salmon (Salmo salar). Fish. Res. 69, 205-209.
Kubecka, J., 1994. Simple model on the relationship between fish acoustical target strength and aspect for high frequency sonar in shallow water. J. Appl. Ichthyol. $10,75-81$

Kubecka, J., Wittingerova, M., 1998. Horizontal beaming as a crucial component of acoustic fish stock assessment in freshwater reservoirs. Fish. Res. 35, 99-106.

Kubecka, J., Duncan, A., 1998. Acoustic size vs. real size relationships for common species of riverine fish. Fish. Res. 35, 115-125.

Kubilius, R., Ona, E., 2012. Target strength and tilt-angle distribution of lesser sandeel (Ammodytes marinus). ICES J. Mar. Sci. 69, 1099-1107.

Lilja, J., Marjomäki, T.J., Riikonen, R., Jurvelius, J., 2000. Side aspect target strength of Atlantic salmon (Salmo salar), brown trout (Salmo trutta), whitefish (Coregonus lavaretus) and pike (Esox lucius). Aquat. Living Resour. 13, 355-360.

Lilja, J., Marjomäki, T.M., Jurvelius, J., Rossi, T., Heikkola, E., 2004. Simulation and experimental measurement of side-aspect target strength of Atlantic salmon (Salmo salar) at high frequency. Can. J. Fish. Aquat. Sci. 61, 2227-2236.

Medwin, H., Clay, C.S., 1998. Fundamentals of Acoustical Oceanography. Academic Press, Boston, pp. 712 .

Mulligan, T., 2000. Shallow water fisheries sonar: a personal view. Aquat. Living Resour. 13 (5), 269-273.

Neilson, J.D., Clark, D., Melvin, G.D., Perley, P., Stevens, C., 2003. The diel vertical distribution and characteristics of pre-spawning aggregations of pollock (Pollachius virens) as inferred from hydroacoustic observations: the implications for survey design. ICES J. Mar. Sci. 60, 860-871.

Pedersen, G., Handegard, N.O., Ona, E., 2009. Lateral-aspect target strength measurements of in situ herring (Clupea harengus). ICES J. Mar. Sci. 66, 1191-1196.

Rasband, W.S., 1997-2014. ImageJ. U. S. National Institutes of Health, Bethesda, MD http://imagej.nih.gov/ij/

Rodríguez-Sánchez, V., Encina-Encina, L., Rodríguez-Ruiz, A., Sánchez-Carmona, R., 2015. Horizontal target strength of Luciobarbus sp. in ex situ experiments: testing differences by aspect angle, pulse length and beam position. Fish. Res. 164, 214-222.

Simmonds, D.M., MacLennan, E.J., 2005. Fisheries Acoustics: Theory and Practice. Fish and Aquatic Resources Series 10, 2nd ed. Blackwell Science, Oxford.

Tichy, F.E., Solli, H., Klaveness, H., 2003. Non-linear effects in a 200-kHz sound beam and the consequences for target-strength measurement. ICES J. Mar. Sci. 60 571-574.

Wanzenbock, J., Mehner, T., Schulz, M., Gassner, H., Winfield, I.J., 2003. Quality assurance of hydroacoustic surveys: the repeatability of fish-abundance and biomass estimates in lakes within and between hydroacoustic systems. ICES J. Mar. Sci. 60, 486-492.

Yule, D.L., 2000. Comparison of horizontal acoustic and purse-seine estimates of salmonid densities and sizes in eleven Wyoming waters. N. Am. J. Fish. Manage. 20, 759-775. 